\title{
The Financial Sustainability of Water Companies: the Italian Case
}

\author{
Felicetta Iovino \\ University of Sannio, Benevento, Italy
}

\begin{tabular}{|c|c|}
\hline & ABSTRACT \\
\hline $\begin{array}{l}2016 \text { Research Leap/Inovatus Services Ltd. } \\
\text { All rights reserved. } \\
\text { DOI: } 10.18775 / \text { jibrm.1849-8558.2015.56.3001 } \\
\text { URL: } \underline{\text { http://dx.doi.org/10.18775/jibrm.1849- }} \\
\underline{8558.2015 .56 .3001}\end{array}$ & \multirow[t]{2}{*}{$\begin{array}{l}\text { Water companies have become an important subject of analysis by international scholars to } \\
\text { contribute to the sustainable development of each country. In this sense, it is also interesting to } \\
\text { verify the financial sustainability of these companies over time. The paper aims to analyze in } \\
\text { particular the financial dynamics of water companies operating in sales phase. To this end, the } \\
\text { financial statements of Italian companies from the AIDA database for the period } 2008-2017 \text { will } \\
\text { be used. In this way, a summary picture will be drawn of the possible financial sustainability of } \\
\text { these companies over time. }\end{array}$} \\
\hline $\begin{array}{l}\text { Keywords: } \\
\text { Public services, Water, Liquidity, Performance, } \\
\text { Sustainability }\end{array}$ & \\
\hline
\end{tabular}

\section{Introduction}

The objective of this paper is to analyze the financial sustainability of Italian water companies. In fact, we will focus on the financial structure of these companies and deepen our belonging to the three geographical areas in which it is possible to distinguish the country. This financial analysis was conducted with reference to a temporal horizon of 10 years and precisely from 2008 to 2017. Attention focused on this period, because during it the main changes in the management of these were carried out companies in Italy. This is attributable to the general reform processes that are characterizing public services in all European countries since the 1990s. In fact, there have been numerous legislative interventions that since the European Union have forced individual national legislators to implement adequate regulations within individual countries. These interventions primarily concerned services of industrial importance. The primary purpose of the European legislator and therefore of those of the individual countries is to guarantee first and foremost a fundamental and inalienable aspect of public services, namely technical quality. The technical quality (Gronroos, C., 2005) is related to the core service, that is to the capacity of the service to satisfy through its technical characteristics precisely the primary needs for which the service is requested. Quiesto is therefore the aspect that characterizes the water service. In addition, there is also the need to guarantee a universal service, that is, a service that has price conditions that allow all citizens potentially to access this service. The start of the transformation of water services in Italy is started by Law No. 36/94, the so-called Galli law. The purpose of this legislative intervention is precisely to implement the European provisions on a national level, but also to concretely implement the very concept of public service. In fact, this law provided for interventions aimed at ensuring the technical quality for consumer citizens. Furthermore, investments in infrastructure were encouraged to make the service offered as universal as possible. The reason for these initiatives was the major shortcomings in access to water in all Italian areas, with very critical peaks particularly in the south of the country. The reasons for these difficulties were basically due to the scarce and inadequate investments in the modernization of the water network. Thus, the national reform law of the sector aimed to multiply and spread investments in the necessary infrastructures, but also to modify the price definition system to be requested from consumers. In fact, the water tariff system is defined until 2011 by an administrative body, the Committee for the supervision of water resources. Subsequently the AEEG, that is the Authority for Electricity and Gas, has seen its competences extended to the water sector, becoming the ARERA, that is the Authority for the regulation of energy, networks and environment, since in 2018 he also took on regulatory duties for the waste sector. Most of the studies on this sector focused on the management characteristics of the related companies. Instead, the financial structure with regard to the actual sustainability of these companies has been 
analyzed in a limited way. Therefore, this paper analyzed the trends of two main financial indices of Italian water companies with reference to a period of 10 years. The priority motive behind this analysis is to understand if the general transformations that are characterizing water services on the basis of the wider transformation of public services, allow these companies to have a real financial sustainability. This financial sustainability is verified in relation to a long time horizon, but also in relation to the different geographical areas of the country. In this sense, three preliminary research questions have been asked:

1. What were the characteristics of the financial index trends analyzed in the three different geographical areas?

2. Are differences or similarities in the trends of the different Italian areas detectable?

3. If there are differences, are they significant from a statistical point of view?

Taking into account the three research questions there are three consequent hypotheses. The $\mathrm{H} 1$ hypothesis is that the water service reform processes have had positive effects on the financial sustainability of water companies. With the $\mathrm{H} 2$ hypothesis we argue however that there are differences in the financial results of the companies located in the three different areas of the country under virtue of previous infrastructure differences not completely filled; these differences in financial results are statistically significant (H3). To this end, the financial dynamics of Italian water companies was assessed by analyzing two different indices: quick ratio and debt / equity ratio. The period under investigation is 10 years, from 2008 to 2017. A trend analysis and ANOVA have been performed. In the further sections, some literature notes on water companies are drawn. The other paragraphs are the specific methodology, the different results, conclusions and the main implications.

\section{Literature Review Notes}

Some authors have investigated the financial performance of water companies and the effects of the transformation of this sector on their value. Vandone et al. (2018)'s study employs a multifactor market model for evaluating if the changes of prices in agriculture and energy affect on the financial performance of water companies. In this sense, a sample of listed companies is analyzed. The main findings suggest some variability of the stock prices of the water companies respect the variations in the prices in energy and agriculture. Suarez-Varela et al. (2017)'s study analyses what type of relation there is between privatization of water companies and related financial performance. The research employs a sample of Spanish water companies. The main findings demonstrate that privatization permits to water companies to have higher results in work management, instead public companies have a low efficiency with operating costs. Maziotis et al. (2018) analyze the variations in net income and in its main components of 10 Welsh and English water companies. The research has been performed during 20 years (1991-2008) in which there were three different reforms. The findings are negative for the analyzed period. The reasons of this negative impact are because of the price of input and the effects of scale. Mellah, T., Ben Amor (2016) try to understand how the regulation affects on the Tunisian water monopoly enterprise. The findings suggest that when the regulation is performance-based the Tunisian water industry increases its efficiency and productivity. Pinto, F.S. et al. (2017)'s study aims to evaluate how environmental and quality factors affects on the financial performance of water companies. To this end, a sample of Portuguese water companies has been used. The findings are generally of a positive type. First of all, private partecipation, water sources and economies of purpose have a positive impact on the financial performance of water companies.

In addiction, the raise in the quality of the provided service increases the financial performances of the same companies. The impacts of the Chinese reform of water companies have been analysed by Li's study (2018). The main aim is understand the financial performance of private Chinese water companies. The anlysis is related to the period 1998-2006 using 12 performance indicators. The findings have found increases in efficiency, in output and financial performance. In this way, the Chinese water companies improve its financial performance by means of the private equity investments. Therefore, thre isn't enough literature that analyse the impacts of the reforms in water companies by means of the financial performance of the related companies. In this way, this study try to understand if there is a positive impact on the financial sustainability of these companies by means of some financial ratios (Iovino, F. 2014; Iovino, F., \& Migliaccio, G., 2016; Iovino, F., \& Migliaccio, G., 2018a; Iovino, F., \& Migliaccio, G., 2018b; Iovino, F., \& Migliaccio, G., 2019a).

\section{Research Methodology}

\subsection{Data Collection and Sample Characteristics}

The data of the AIDA database were used in order to obtain answers to the research questions and at the same time also to verify the hypotheses posed. The analysis of the financial dynamics of Italian water companies was analyzed through the use of two indices, the quick ratio and the debt / equity ratio. The verification of the impacts of the reforms carried out was carried out by verifying these indices for a period of 10 years, ie from 2008 to 2017. The identification of these companies took place using the NACE rev. 2. The enterprises were classified according to the NACE code rev.2. The maximum number of companies identified in the period under investigation is 305 . It was then chosen to analyze only the companies available for both indices in all the years considered. The total number of companies making up the sample is therefore equal to 122 companies. As a next step, we chose to identify different groups through the use of the geographical location as a discriminating variable. In this sense, there are three geographical areas in which Italy is traditionally distinct: 
north, central and south. So the subdivision of the sample of Italian water companies was as follows: $58 \%$ in the Northern area, $23 \%$ in the Central area and $19 \%$ in the Southern ones (figures 1).

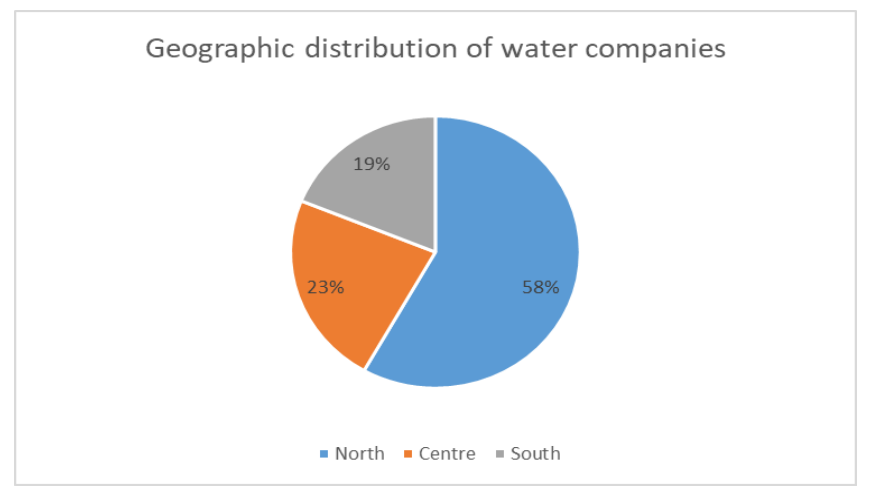

Figure 1: Geographic distribution of water companies Source: our elaboration - geographic distribution of Italian water companies

\subsection{Used Method}

A trend analysis was performed for the 2008-2017 period for each index and geographical area. Subsequently ANOVA was used to identify the presence of any similarities or differences in the values recorded in the two indices between the different geographical areas. If the null hypothesis is true, all the elements are equal to each other, while the alternative hypotheses indicate that at least one value is different. The independent variables used are the different geographical areas, while the indices are the independent variables. ANOVA (oneway) was chosen because in addition to the verification of the presence of statistically significant differences, this analysis is useful when the two variables under investigation are analyzed separately (Saunders, et al., 2009).

\section{Findings and Discussion}

\subsection{Analysis of Trends and of Variance}

Quick ratio (liquid assets / current debts) is an index that expresses the company's liquidity with respect to current payables. In fact, it refers to the ability of the company to be able to deal with current debts exclusively by relying on the current liquidity, ie excluding the stock. In fact, the latter may prove to be difficult and not immediately transferable. It is therefore certainly an index to be analyzed to verify the solvency of the company in the short and very short term, that is to the commitments assumed towards third parties. It is therefore a condition of operation in the time of the company. During the 10 years analyzed the value of the quick ratio ranges from a minimum of 1.3 to a maximum of 2.1 , referring to the geographical location as a discriminating element. An optimal value of this index is open to 2 . Figure 2 shows that only the southern regions are able to approach an optimal value unlike the companies present in the other two areas. Furthermore, the trends over the 10 years are quite stable. However, it is possible to see a slight upward trend starting from 2012 for all companies in different geographical areas. Only for the enterprises of the center there is a slight negative trend from 2008 to 2012, to then have a decisive growth in the following years. Companies in the north are experiencing a growing trend. In fact, from a value of 1.4 in 2008 they reach a value of 1.6 in 2017. The liquidity of southern firms, as can be seen from the graph, is higher than that recorded in the other two areas of Italy. Therefore, the best liquidity over time is also very close to the optimal values.

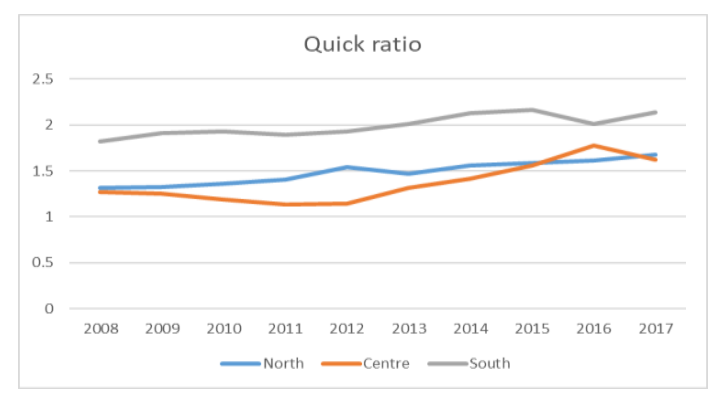

Figure 2: Trend of quick ratio according to geographic localization

Debt / equity (debt / equity) indicates the financial dependence of the company on third-party sources both in the short and long term. The optimal value of this index is open to 2 . In fact, in this case the impression uses the capacity of the debt to raise the profitability of the company. However, higher values indicate a risky situation in which the company may lose its economic independence. It is therefore an index that must be used carefully. During the 10 years analyzed, the index assumes values greater than 2 in companies in the North and South, indicating a situation of serious risk, but at the same time full use of financial leverage.

The values in fact range from a minimum of 0.4 to a maximum of 4.5. The highest values are recorded in 2008 in all regions. However, while for the regions of the center these values remain throughout the decade even below 2 , the situation in the other areas is different. In fact, companies in the south and the north have high motorcycle values in 2008 and then have a very decreasing trend until 2010 in 2011 . The northern regions have a further peak in 2011 with a value of 4.5 . The central regions certainly have the most stable trend over time, albeit also decreasing. Thus, decrease occurs in conjunction with the process of transforming the regulation of these companies. They are in fact called to greater financial sustainability also due to the effect of tariff variations. In fact, since 2011 they are determined by ARERA (Iovino, F., 2012; Iovino, F., 2015), Italian Authority for the regulation of energy networks and environment (Iovino, F., \& Migliaccio, G., 2019b). 


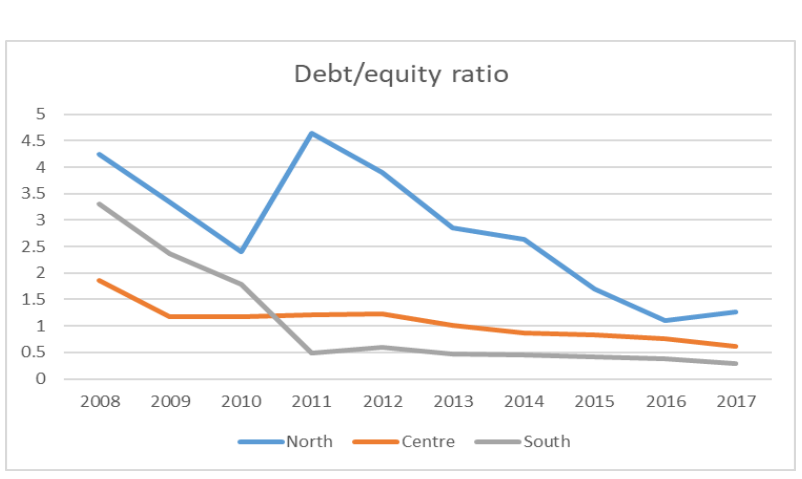

Figure 3: Trend of debt/equity ratio following the geographical area

Therefore, from the analysis of the trends carried out in relation to the quick ratio and the debt

I equity ratio over the course of the decade, the situation has improved in conjunction with the implementation of reforms by the legislator in the conduct of Italian water companies. This is particularly evident for the debt / equity ratio that passes from a highly risky situation to a more contained one and around the equilibrium value. In this way, the company is able to exploit the leverage of the debt, but at the same time to have a nonrisky position towards third parties. The quick ratio also assumes slightly increasing values in all geographical areas. It can therefore be stated that the H1 hypothesis is verified. Furthermore, the values of the two indexes analyzed appear quite different in the different geographical areas. However, there is a certain similarity between north and center due to the quick ratio, and in some years between center and south for the debt / equity ratio. Substantially however, even the hypothesis $\mathrm{H} 2$ is verified. Therefore, the results in terms of financial sustainability of water companies by virtue of the reforms carried out are substantially positive, but with variations in the relative impacts in the various geographical areas.

\subsection{Analysis of Variance}

The results of the ANOVA (one-way) test are shown in table 1. The geographical variable was used as an independent variable. The table shows a statistically significant difference between at least two of the values included in the sample. In fact, $(\mathrm{F}(2,27)$ $=42.59, \mathrm{p}=4.45941 \mathrm{E}-09)$ and $\mathrm{F}>\mathrm{F}$ crit with a $\mathrm{p}$ value less than 0.05 .

Table 1: Quick ratio - ANOVA (one-way) using as an independent variable the geographic area

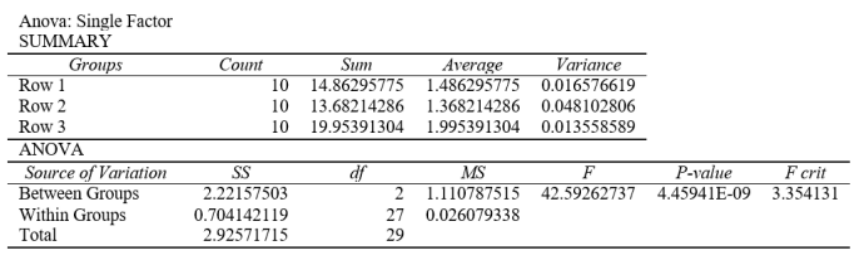

Significance level $\mathrm{p}>0.05$
There is therefore a statistically significant difference between the quick ratio values recorded in the period under investigation when the geographical variable is considered as an independent variable. Also in the case of the debt / equity ratio ANOVA (one-way) confirms that there is a statistically significant difference between the values achieved by Italian water companies in the various geographical areas. In fact, $\mathrm{F}(2,27)=$ 11.0034, $\mathrm{p}=0,00032$ ) and $\mathrm{F}>\mathrm{F}$ crit with a $\mathrm{p}$ value less than 0.05 .

Table 2: Debt/equity ratio - Analysis of variance with the geographic area as an independent variable

\begin{tabular}{|c|c|c|c|c|c|c|}
\hline \multicolumn{7}{|l|}{$\begin{array}{l}\text { Anova: Single Factor } \\
\text { SUMMARY }\end{array}$} \\
\hline Groups & Count & Sum & Average & Variance & & \\
\hline Row 1 & 10 & 28.08704225 & 2.80870423 & 1.517868 & & \\
\hline Row 2 & 10 & 10.73857143 & 1.07385714 & 0.123813 & & \\
\hline Row 3 & 10 & 10.57695652 & 1.05769565 & 1.119271 & & \\
\hline \multicolumn{7}{|l|}{ ANOVA } \\
\hline Source of Variation & SS & $d f$ & $M S$ & $F$ & $P$-value & F crit \\
\hline Between Groups & 20.2532887 & 2 & 10.1266444 & 11.00342 & 0.00032 & 3.354131 \\
\hline Within Groups & 24.8485729 & 27 & 0.92031752 & & & \\
\hline Total & 45.1018617 & 29 & & & & \\
\hline
\end{tabular}

Significance level $\mathrm{p}>0.05$

ANOVA therefore confirms for both indices that there is a statistically significant difference between the different geographical areas of the country. The hypothesis H3 is therefore confirmed.

\section{Conclusion}

The water sector, like other public services, has been characterized by profound reforms since the 1990s. In fact, the priority objectives were on the one hand to guarantee all citizens access to this resource as an indispensable asset and therefore a universal service. On the other hand, it will also be possible to carry out all those transformations that are capable of ensuring an adequate saving of resources in supplying public finance problems both nationally and locally. All these reasons led to an increase in infrastructure investments with the primary aim of ensuring the technical quality of the service. (Gronroos, C., 2005; Iovino, F., 2012; Iovino, F., 2015). In this general framework of reforms, the present work carries out an analysis of two financial indices relative to the period (2008-2017). It highlights substantial positive effects of the reform processes on the financial sustainability of Italian water companies. The quick ratio appears to be positively affected by the reform processes.

In fact, we note a slight but constant increase in its values over time in all the geographical areas analyzed. This implies that Italian water companies can count over time on greater liquidity towards third parties. They will therefore be able to deal with the requests coming from their creditors in the short term with relative ease, using only their own liquidity. This is also the result above all of the change in tariff regulation and a general increase in tariffs over time. The debt / equity ratio also assumes decreasing values over time. This is the result of a more careful 
financial management aimed at reducing risk positions towards third parties. In fact, the index is reported from very high values and therefore also risky in 2008, to very low values in 2017. This occurs in all geographical areas indicating a reduced recourse to third-party assets and therefore a less risky situation, but at the same time that it does not fully utilize the advantages deriving from the financial lever. This distinguishes all geographical areas. However, for both indices there are differences between the different geographical areas. This implies that the infrastructural, but also financial differences of these companies are not completely overcome. However, the common element is that overall financial sustainability is however positive, but with obvious differences between the different geographical areas. The differences between the different geographical areas are confirmed both by the trend analysis and by the ANOVA. This paper is an important contribution, because it carries out an analysis on almost all the population of Italian water companies and not just a sample. Furthermore, it is carried out with reference to a fairly large period, 10 years. It is such as to capture some significant changes due to the legislative interventions that have occurred over time. The present work also has limitations deriving also from the use of only two financial indices. However it represents an exploratory study. To this it is added that only the companies of which all the values for the two indexes analyzed during the 10 years of investigation are available are considered. The paper also does not consider the merger and aggregation processes that have characterized the sector. These limits also constitute future research guidelines. Indeed, further investigations will be aimed at analyzing a larger number of both income and financial indices (Iovino, F., in press). Comparative comparisons can be made with the results of companies from other European countries, all being involved in a general reform process. Also interesting is the verification of non-financial variables, including certainly the cultural and relational ones (Iovino, F., 2012; Iovino, F., 2015).

\section{References}

- Gronroos, C. (2005) What can a service logic offer marketing theory, Helsinki: Library of Swedish School of Economics and Business Administration.

- Iovino, F. (2012). Le scelte delle politiche di marketing delle imprese energetiche.

- Management delle utilities, 4, 23-35.

Iovino, F. (2014). L'internet marketing nelle imprese energetiche: il caso di un'impresa elettrica romana.

Mercati e competitività, 3, 141-161. $\underline{\text { Crossref }}$

- Iovino, F. (2015). Relationship marketing by Energy companies. Review of International comparative management, 16(5), 558-573.

- Iovino, F., Migliaccio, G. (2016). E-marketing by energy companies. 9th Annual Conference of the Euromed Academy of Business, "Innovation, Entrepreneurship and Digital Ecosystems”, 14-16 September 2016, Warsaw,
Poland, Book of Conference Proceedings, Euromed Press, 1036-1048.

- Iovino, F., Migliaccio, G. (2018a). Profitability dynamics of tourism companies during the crisis period (2007-2015). In Vrontis D., Weber Y., Tsoukatos E. (Eds), Conference readings book proceedings, 11th Annual Conference of the EuroMed: Research Advancements in National and Global Business. Theory and Practice, Valletta, Malta,September 12th-14th, EuroMed Press: Cyprus, 663-677.

- Iovino, F., Migliaccio, G. (2018b). Financial dynamics of tourism companies, travel agencies and tour operators, during the crisis period. In Conference Proceedings: 2nd International Scientific Conference on Economics and Management -EMAN 2018: Economics \& Management: How to Cope With Disrupted Times, Ljubljana, Slovenia, March 22th, Printed by: All in One Print Center, Belgrade, 693-702. Crossref

- Iovino, F., Migliaccio, G. (in press). Financial Dynamics of Energy Companies During Global Economic Crisis. International Journal of Business and Globalisation, (doi: 10.1504/IJBG.2019.10011698).

- Iovino, F., Migliaccio, G. (2019b). Energy companies and sizes: An opportunity? Some empirical evidences. Energy Policy, Vol. 128, May 2019, DOI: 10.1016/j.enpol.2019.01.027, 431-439. Crossref

- Iovino, F., Migliaccio, G., (in press). Mobile marketing and strategy by energy companies.

- International journal of Public Sector and Performance Management.

- Iovino, F., (in press). The profitability of water companies during ten years. In Conference Proceedings: 3rd International Scientific Conference on Economics and Management - EMAN 2019: Economics \& Management: How to Cope With Disrupted Times, Ljubljana, Slovenia, March 28th, Printed by: All in One Print Center, Belgrade. Crossref

- Li, L., (2018) Private sector participation and performance of county water utilities in China, China Economic Review, Vol. 52, pag. 30-53, DOI: 10.1016/j.chieco.2018.06.001. Crossref

- Maziotis, A., Saal, D.S., Thanassoulis, E., and MolinosSenante, M. (2018) Profit change and its drivers in the English and Welsh water industry: is output quality important?, Water Policy, Vol. 20, n. 5, pag. 995-1012, DOI: 10.2166/wp.2014.151. $\underline{\text { Crossref }}$

- Mellah, T., Ben Amor, T. (2016) Performance of the Tunisian Water Utility: An input- distance function approach, Utilities Policy, Vol. 38, pag. 18-32, DOI: 10.1016/j.jup.2015.11.001 Crossref

- Pinto, F.S., Simoes, P., Marques, R.C., (2017), Water services performance: do operational environment and quality factors count?, Urban Water Journal, Vol. 14, n. 8, pag. 773-781, DOI: 10.1080/1573062X.2016.1254254 Crossref 
- Saunders, M., Lewis, P., and Thornhill, A., (2009), "Research methods for business students", (5th ed.), Pearson Education Limited, Essex, UK.

- Suarez-Varela, M., de Los Angeles Garcia-Valinas, M., Gonzalez-Gomez, F., Picazo- Tadeo, A.J. (2017) Ownership and Performance in Water Services Revisited: Does Private Management Really Outperform Public?, Water Resources Management, Vol. 31, n. 8, pag. 2355-2373, Special Issue, DOI: $10.1007 / \mathrm{s} 11269-016-1495-3$ Crossref

- Vandone, D., Peri, M., Baldi, L., Tanda, A., (2018) The impact of energy and agriculture prices on the stock performance of the water industry, Water Resources And Economics, Vol. 23, pag. 14-27, DOI: 10.1016/j.wre.2018.02.002. Crossref 